\title{
Risk of subsequent invasive breast carcinoma after in situ breast carcinoma in a population covered by national mammographic
} screening

\author{
R Rawal ${ }^{*, 1}$, J Lorenzo Bermejo' and K Hemminki ${ }^{1,2}$ \\ 'German Cancer Research Center, Division of Molecular Genetic Epidemiology, Im Neuenheimer Feld 580, Heidelberg D-69 I 20, Germany; ${ }^{2}$ Department \\ of Biosciences at Novum, Karolinska Institute, Huddinge, Sweden
}

Sweden was the first country to establish a nationwide breast cancer screening service. We used the Swedish Family-Cancer Database to evaluate the risk of invasive carcinoma after in situ carcinoma of the breast. Risk estimates for contralateral and ipsilateral invasive malignancies following age and histology specific in situ breast carcinomas were calculated using Poisson's regression analysis. The agreement between concordant and discordant morphologies of invasive and in situ breast cancer was measured using the kappa statistic. Women with in situ breast cancer showed a relative risk of 2.03 for contralateral and 3.94 for ipsilateral invasive breast cancer. The risk was higher for in situ carcinomas diagnosed before the age of 50 years and after lobular in situ breast cancers. A comparison of the risks during the past decades suggested that the risk of ipsilateral breast cancer has increased in Sweden but that of contralateral breast cancer has remained unchanged. In situ and the subsequent invasive breast cancers did not seem to share their morphologies.

British Journal of Cancer (2005) 92, 162- 166. doi: I0.1038/sj.bjc.6602250 www.bjcancer.com

Published online 30 November 2004

(C) 2005 Cancer Research UK

Keywords: DCIS; LCIS; in situ breast cancer; invasive breast cancer

The most common morphologies of carcinoma in situ of the breast are ductal (DCIS) and lobular carcinoma (LCIS). In Sweden, the incidence of DCIS has increased since the introduction of mammographic screening, representing now $15-20 \%$ of all breast malignancies, compared with $5 \%$ of the cases in prescreening era (Pinder and Ellis, 2003). The incidence of LCIS has also increased, but appreciably slower than that of DCIS (Ernster et al, 1996). In addition to the different incidence patterns, mostly due to mammographic characteristics, DCIS is regarded as a local precursor of invasiveness, while LCIS is merely considered a general risk factor for developing invasive carcinoma, including a contralateral malignancy (Claus et al, 2003; Page, 2004). The estimated risks of invasive breast cancer after in situ carcinoma are heterogeneous in the literature: DCIS has been associated with a four- to 10-fold risk increment; the estimates of the relative risk (RR) after LCIS vary from 2 to 11 (Page et al, 2000; Warnberg et al, 2000).

Sweden has been the first country that implemented a nationwide mammographic screening. The first service was started in year 1986 and it was extended to a complete national coverage by year 1997 (Olsson et al, 2000). One consequence of screening has been an earlier detection of breast cancer (Zahl et al, 2004). The conservative breast surgery may have also influenced the clinical course and prognosis of breast cancer (Kestin et al, 2000). The aim

*Correspondence: Dr R Rawal; E-mail: r.rawal@dkfz.de

Received 23 August 2004; revised 13 October 2004; accepted 14 October 2004; published online 30 November 2004 of the present study was to evaluate the risk of invasive breast carcinoma after in situ carcinoma in Sweden. The estimation was based on cancers diagnosed between 1993 and 2000, thus taking into account the possible impact of screening and recent advances in management of in situ breast cancers. Risk estimates were derived for contralateral and ipsilateral invasive malignancies following age- and histology-specific in situ breast carcinomas. The change in the risk of invasive carcinoma after in situ breast cancer during the last 20 years in Sweden was also explored.

\section{MATERIALS AND METHODS}

The Swedish Family-Cancer Database was created in the mid-1990s by linking census information, death notifications and the administrative family register to the Swedish Cancer Registry at Statistics Sweden (Hemminki, 2001; Hemminki et al, 2001). The Database was updated at the end of 2002 to include more than 10 million individuals. The present analysis considered diagnoses made between 1993 and 2000 and included 3802 in situ breast and 35480 invasive breast cancers in a population of five million women. The Swedish Cancer Registry is based on compulsory reports of individual cases provided by clinicians/pathologists or cytologists and is considered to have almost $100 \%$ completeness (The National Board of Health and Welfare Stockholm, 2002). The incidence of cancer in the Database is similar to the incidence in the Cancer Registry (Hemminki et al, 2001; Plna and Hemminki, 2001). Four-digit diagnostic codes from the seventh revision of the International Classification of Diseases (ICD-7) and subsequent 
ICD classifications are available. In the current study, carcinoma of breast was indicated by ICD-7 code 170 . Histology was recorded according to the Systemized Nomenclature of Medicine (SNOMED). Invasive breast cancers were classified as: ductal carcinoma (SNOMED code 85003), lobular carcinoma (85203) and comedo carcinoma (85013). In situ breast cancers were also classified in three categories: ductal carcinoma (85002), lobular carcinoma (85202) and comedo carcinoma (85012). Breast cancer is often of mixed morphology at presentation and only the main type was recorded in the Swedish Cancer Registry (Harris et al, 1993). Invasive breast cancers diagnosed after in situ malignancies in the other breast were classified as contralateral, but as ipsilateral if they occurred in the same breast. Only invasive cancers diagnosed at least 1 month after diagnosis of the in situ breast carcinoma were included in the present study. Incidence rates of histology-specific breast cancers were standardised for age according to the European population. Variations in incidence rates from 1993 to 2000 were studied by log linear regression analyses based on the maximum-likelihood method (Figure 1).

Follow-up began at the age of 21 years (earliest age at diagnosis of invasive breast cancer), the date of immigration, the date of diagnosis of in situ breast cancer or 1 January 1993, whichever occurred last. Follow-up ended at diagnosis of the first primary
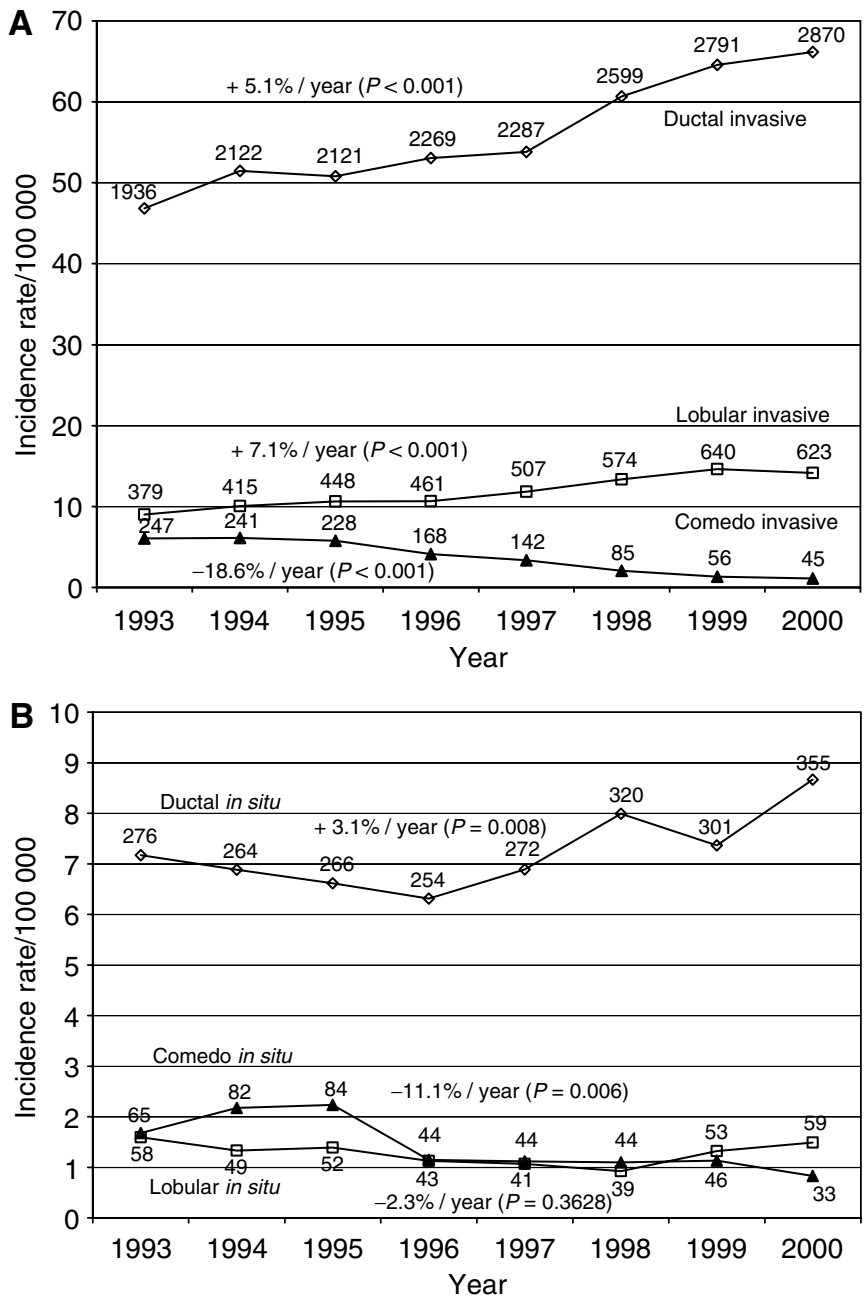

Figure I Trends in incidence rates of invasive $(\mathbf{A})$ and in situ breast cancer (B) according to histologic subtype, based on the Swedish FamilyCancer Database. Incidence rates are adjusted for age (European standard). The mean annual increase or decrease is presented at the curve. The numbers of observed cases are presented for each year. malignancy, death date, emigration date or 31 December 2000, whichever occurred first. Person-years and cases of invasive breast cancer were counted and grouped by age, family history, age at first birth and the presence or absence of in situ breast cancer. A Poisson regression analysis was applied to the data using the Genmod procedure of the SAS program (SAS/STAT ${ }^{\mathbb{R}}$ User's guide, 1999). The results are shown as an RR, with $95 \%$ confidence limits (95\% CI). Risk estimates were also calculated for the periods 1981-1990, 1991-1995 and 1996-2000 in order to investigate possible changes during the last 20 years in Sweden. Differences in the time of follow-up and age of the women among the three periods were taken into account by indirect standardisation before Poisson's regression, using the period 1996-2000 as reference.

The kappa statistic was used as a measure of agreement between concordant and discordant morphologies of invasive and in situ breast cancer. Kappa takes values between -1 and 1 , where 0 indicates no determination and -1 or 1 would indicate that the morphology of the invasive carcinoma is completely determined by the histology of the prior in situ carcinoma. Values of the kappa statistic between 0.40 and 0.60 would suggest a moderate concordance.

\section{RESULTS}

The incidence rate of invasive ductal cancer increased in the period $1993-2000$ from 46.8 to $66.1 / 100000(+5.1 \%$ per year $)$ and invasive lobular cancer showed an increase from 9.0 to 14.2 / $100000(+7.1 \%$ per year). A striking decrease was found for the comedo histology, with incidence rates from 6.1 to $1.1 / 100000$ ( $-18.6 \%$ per year). In situ ductal cancer increased from 7.2 to $8.7 /$ $100000(+3.1 \%$ per year $)$ and, interestingly, the incidence of in situ lobular cancer remained constant (1.6/100000). In situ comedo cancer showed a decreasing incidence rate from 1.7 to $0.8 / 100000(-11.1 \%$ per year $)$.

The results of the Poisson regression analysis for contralateral breast cancer are presented in Table 1 . The diagnosis of in situ breast carcinoma resulted in a two-fold increase in the risk of invasive cancer in the contralateral breast; the increase was particularly high if the in situ breast lesion was diagnosed before the age of 50 years. The risk increased with the time after diagnosis of the in situ carcinoma, although the increment was not statistically significant. The lobular histology of in situ breast carcinoma was associated with the highest risk for contralateral invasive breast cancer. The diagnosis of in situ carcinoma resulted in an RR of 3.94 for invasive ipsilateral cancer (Table 2). Comedo in situ carcinoma was associated with the highest risk of ipsilateral invasive breast cancer $(\mathrm{RR}=5.02)$.

The risks of contralateral invasive cancer after in situ breast cancer slightly increased during the period 1991-1995 and it decreased thereafter, but were not statistically significant (Figure 2A). In contrast, the risks of ipsilateral invasive breast cancer after in situ breast cancer in 1991-1995 and 1996-2000 were two times higher than in 1981-1990 (Figure 2B); the risk differences were statistically significant. The increase in the risk of ipsilateral breast cancer was mostly associated with in situ carcinomas diagnosed at ages 50-60 years (results not shown).

Table 3 shows kappa measures of agreement between concordant in situ and invasive morphologies. Kappa values for all concordant and discordant histologies (results not shown for discordant histologies) were lower than 0.40 , thus suggesting that the histology of the invasive cancers was not determined by the morphology of the preceding in situ carcinoma.

\section{DISCUSSION}

The treatment for the first breast cancer, the intense medical follow-up and the self-observation of the patient complicate the 
Table I Contralateral invasive breast cancer subsequent to in situ carcinoma of breast analysed in Poisson's regression model

\begin{tabular}{|c|c|c|c|c|}
\hline Parameter & & $N$ & $\mathbf{R R}$ & $95 \% \mathrm{Cl}$ \\
\hline \multicolumn{5}{|c|}{ In situ breast cancer } \\
\hline No & & 34803 & 1.00 & \\
\hline Yes & & 54 & 2.03 & $1.55-2.65$ \\
\hline \multirow[t]{2}{*}{ No } & & 34803 & 1.00 & \\
\hline & $\begin{array}{l}\text { Age at diagnosis of } \\
\text { in situ breast cancer }\end{array}$ & & & \\
\hline \multirow[t]{4}{*}{ Yes } & $C<50$ & 15 & 3.02 & $1.82-5.02$ \\
\hline & $50-60$ & 22 & 2.09 & $1.38-3.18$ \\
\hline & $60-70$ & 11 & 1.62 & $0.90-2.92$ \\
\hline & $\geqslant 70$ & 6 & 1.38 & $0.62-3.07$ \\
\hline \multirow[t]{2}{*}{ No } & & 34803 & 1.00 & \\
\hline & $\begin{array}{l}\text { Time after diagnosis of } \\
\text { in situ breast cancer }\end{array}$ & & & \\
\hline \multirow[t]{3}{*}{ Yes } & $\int 1-12$ months & 9 & 1.61 & $0.84-3.10$ \\
\hline & 12-24 months & 9 & 1.58 & $0.82-3.03$ \\
\hline & $l \geqslant 24$ months & 36 & 2.34 & $1.69-3.25$ \\
\hline \multirow[t]{2}{*}{ No } & & 34803 & 1.00 & \\
\hline & $\begin{array}{l}\text { Histology of in situ } \\
\text { breast cancer }\end{array}$ & & & \\
\hline \multirow[t]{4}{*}{ Yes } & Cuctal & 34 & 1.96 & $1.40-2.74$ \\
\hline & Lobular & 6 & 3.16 & $1.42-7.03$ \\
\hline & Comedo & 10 & 2.79 & $1.50-5.18$ \\
\hline & Others & 4 & 1.06 & $0.40-2.83$ \\
\hline
\end{tabular}

$\mathrm{RR}=$ relative risk; $\mathrm{Cl}=$ confidence interval. Data were additionally adjusted for age, family history, parity and age at first birth. Bold = the RR was statistically higher than I.00.

Table 2 Ipsilateral invasive breast cancer subsequent to in situ carcinoma of breast analysed in Poisson's regression model

\begin{tabular}{|c|c|c|c|c|}
\hline Parameter & & $N$ & $\mathbf{R R}$ & $95 \% \mathrm{Cl}$ \\
\hline \multicolumn{5}{|c|}{ In situ breast cancer } \\
\hline No & & 34803 & 1.00 & \\
\hline Yes & & 105 & 3.94 & $3.26-4.78$ \\
\hline \multirow[t]{2}{*}{ No } & & 34803 & 1.00 & \\
\hline & $\begin{array}{l}\text { Age at diagnosis of } \\
\text { in situ breast cancer }\end{array}$ & & & \\
\hline \multirow[t]{4}{*}{ Yes } & $(<50$ & 37 & 7.47 & $5.4 I-10.31$ \\
\hline & $50-60$ & 36 & 3.42 & $2.47-4.75$ \\
\hline & $60-70$ & 24 & 3.53 & $2.36-5.26$ \\
\hline & $\geqslant \geqslant 70$ & 8 & 1.84 & $0.92-3.67$ \\
\hline \multirow[t]{2}{*}{ No } & & 34803 & 1.00 & \\
\hline & $\begin{array}{l}\text { Time after diagnosis of } \\
\text { in situ breast cancer }\end{array}$ & & & \\
\hline \multirow[t]{3}{*}{ Yes } & $\int 1-12$ months & 17 & 3.05 & $1.89-4.90$ \\
\hline & $12-24$ months & 26 & 4.56 & $3.10-6.69$ \\
\hline & $l \geqslant 24$ months & 62 & 4.04 & $3.15-5.18$ \\
\hline \multirow[t]{2}{*}{ No } & & 34803 & 1.00 & \\
\hline & $\begin{array}{l}\text { Histology of } \\
\text { in situ breast cancer }\end{array}$ & & & \\
\hline \multirow[t]{4}{*}{ Yes } & (Ductal & 66 & 3.80 & $2.98-4.84$ \\
\hline & Lobular & 9 & 4.74 & $2.46-9.11$ \\
\hline & Comedo & 18 & 5.02 & $3.16-7.96$ \\
\hline & COthers & 12 & 3.19 & $|.8 \mathbf{l}-5.6|$ \\
\hline
\end{tabular}

$\mathrm{RR}=$ relative risk; $\mathrm{Cl}=$ confidence interval. Data were additionally adjusted for age, family history, parity and age at first birth. Bold = the RR was statistically higher than 1.00 .
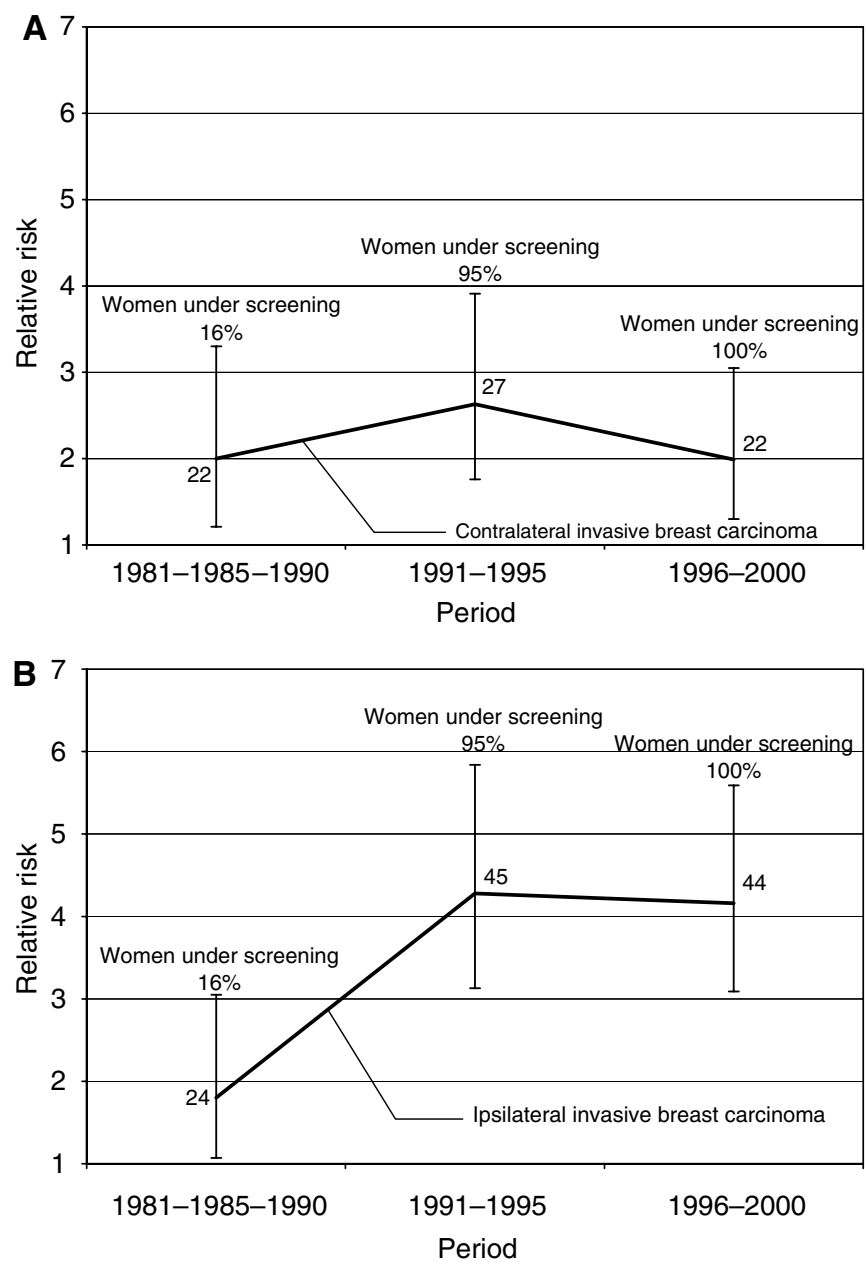

Figure 2 Relative risk of contralateral $(\mathbf{A})$ and ipsilateral $(\mathbf{B})$ invasive breast carcinoma subsequent to in situ breast carcinoma for different periods.

epidemiology of second breast cancers. Moreover, two breasts are at risk for the first cancer, but only one of them is at risk for ipsilateral or for contralateral breast cancer. Treatment, follow-up and definition differences have probably contributed to the incongruent results for invasive breast cancer after in situ carcinoma in the literature (Chen et al, 1999). The RRs shown in the present study were calculated after dividing the second breast cancers into contralateral and ipsilateral breast cancers.

All in situ breast carcinomas are premalignant, being possible precursors to invasive disease capable of metastasis (Dupont and Page, 1985; Page et al, 1985, 2000; Page and Dupont, 1990; London et al, 1992). The potential for progression to invasive cancer has been measured in earlier studies (Franceschi et al, 1998; Ottesen et al, 2000; Crocetti et al, 2001; Warnberg et al, 2001). However, the number of cases analysed previously was small. One study considered breast cancers in the period 1980-1992, that is, before and during the establishment of screening services in Sweden (Warnberg et al, 1999). Earlier diagnosis due to screening and recent advances in the treatment of in situ carcinoma have resulted in better survival rates for patients and a higher incidence for invasive carcinoma. An advantage of the present study was the adjustment for age, family history and parity in the Poisson regression analyses. Unfortunately, information on possible confounders such as treatment received, use of contraceptives and stage of the cancer or tumour size was not available. 
Table 3 Kappa measures of agreement between concordant in situ and invasive morphology

\begin{tabular}{|c|c|c|c|c|c|c|}
\hline & \multicolumn{6}{|c|}{ Kappa } \\
\hline & $N$ & All morphologies & $N$ & Ductal (Ductal+comedo) & $N$ & Lobular \\
\hline All in situ followed by invasive & 140 & 0.19 & 62 & 0.21 & 5 & 0.34 \\
\hline Invasive in contralateral breast & 54 & 0.14 & 24 & 0.16 & 2 & 0.29 \\
\hline Invasive in ipsilateral breast & 105 & 0.18 & 47 & 0.18 & 5 & 0.36 \\
\hline
\end{tabular}

The increased incidence of invasive ductal and lobular breast cancers found in the present study was similar to previous reports (Levi et al, 1997; Li et al, 2003; Verkooijen et al, 2003). The reduction in the incidence of comedo breast cancer is probably attributable to modifications in pathological classification criteria. The incidence of DCIS increased in the period 1993-2000, which was to a small extent due to the reclassification of comedo in situ carcinomas as DCIS. In contrast, the incidence of LCIS did not change. Earlier reports have shown increases in the incidence of DCIS and LCIS (Simon et al, 1993; Choi et al, 1996; Levi et al, 1997). The different incidence patterns found for DCIS and LCIS in the present study may be partly attributable to the low calcification of lobular tumours, which hampers their detection by mammography.

In situ breast carcinoma diagnosed before the age of 50 years was associated with the highest risk of invasive cancer, the difference from other age groups was even statistically significant for ipsilateral breast cancer. In patients with mammographically detected ductal carcinoma in situ, treated with breast-conserving therapy, young patient age has been reported to be a risk factor for local recurrence (Kestin et al, 2000). Our results were similar to earlier studies, which have shown higher risks for invasive breast cancer in women with in situ cancer diagnosed at young ages (Franceschi et al, 1998; Crocetti et al, 2001; Warnberg et al, 2001; Claus et al, 2003). The risk of invasive breast cancer increased with the time after diagnosis of in situ carcinoma, but the number of cases analysed was small and the trend was not statistically significant. Our data agree with earlier results, that the highest risk of invasive cancer is reached after 42 to 60 months after diagnosis of in situ lesions. (Franceschi et al, 1998; Ottesen et al, 2000; Warnberg et al, 2000, 2001; Crocetti et al, 2001).

The risk of invasive cancer in the contralateral and ipsilateral breasts was higher after lobular than after ductal carcinoma in situ. Our results therefore disagree with the report suggesting that this risk was higher after DCIS than after LCIS (Warnberg et al, 2000). A higher incidence of DCIS due to screening may have diluted the risk of the subsequent invasive breast cancer, whereas the incidence of LCIS and its corresponding risk seem to have been only slightly modified.

\section{REFERENCES}

Chen Y, Thompson W, Semenciw R, Mao Y (1999) Epidemiology of contralateral breast cancer. Cancer Epidemiol Biomarkers Prev 8: 855-861

Choi WS, Parker BA, Pierce JP, Greenberg ER (1996) Regional differences in the incidence and treatment of carcinoma in situ of the breast. Cancer Epidemiol Biomarkers Prev 5: 317-320

Claus EB, Stowe M, Carter D, Holford T (2003) The risk of a contralateral breast cancer among women diagnosed with ductal and lobular breast carcinoma in situ: data from the Connecticut Tumor Registry. Breast 12: $451-456$

Crocetti E, Miccinesi G, Paci E, Zappa M (2001) Incidence of second cancers among women with in situ carcinoma of the breast. Breast 10: $438-441$
The estimated risk of ipsilateral invasive cancer after in situ lesions was almost two times higher than the corresponding risk of contralateral breast cancer. This risk difference was only found after 1991, and was statistically significant for the period 19962000. Breast-conserving surgery became the treatment of choice for early breast cancer in Sweden during the 1980s, especially in areas with population-based screening (Fredriksson et al, 2001). The proportion of women receiving conservative surgery increased from $7 \%$ in 1980 to $51 \%$ in 1996 (Lindqvist et al, 2002). Inadequately treated in situ breast carcinoma, for example, insufficient margin control, may have contributed to the observed risk increase (Yau et al, 2002; Fredriksson et al, 2003; Kerlikowske et al, 2003; Khan and Newman, 2004).

The suggestion of previous studies that in situ and subsequent invasive cancers share morphological features (Habel et al, 1997; Franceschi et al, 1998) could not be confirmed in the present study. However, we found the highest concordance for the lobular histology, in agreement with earlier studies, which showed that LCIS is often followed by lobular invasive breast cancer (Lishman and Lakhani, 1999; Fisher et al, 2004). The present study is congruent with earlier analyses on the genetic determination of the morphology of invasive breast cancer based on the Swedish Family-Cancer Database (Hemminki and Granstrom, 2002).

We conclude that the incidence of in situ carcinoma of the breast has increased in the last decade and that the introduction of screening and new treatments in Sweden seems to have modified the pattern of risk of invasive cancer after in situ carcinoma. The risk of invasive cancer in the ipsilateral breast has increased. Women with LCIS are at higher risk of invasive breast cancer than women with DCIS. The risks estimated in this study may help in clinical counselling.

\section{ACKNOWLEDGEMENTS}

This study was supported by Deutsche Krebshilfe and the Swedish Cancer Society. The Family-Cancer Database was created by linking registers maintained by Statistics Sweden and the Swedish Cancer Registry.
Dupont WD, Page DL (1985) Risk factors for breast cancer in women with proliferative breast disease. $N$ Engl J Med 312: 146-151

Ernster VL, Barclay J, Kerlikowske K, Grady D, Henderson C (1996) Incidence of and treatment for ductal carcinoma in situ of the breast. JAMA 275: $913-918$

Fisher ER, Land SR, Fisher B, Mamounas E, Gilarski L, Wolmark N (2004) Pathologic findings from the National Surgical Adjuvant Breast and Bowel Project: twelve-year observations concerning lobular carcinoma in situ. Cancer 100: $238-244$

Franceschi S, Levi F, La Vecchia C, Randimbison L, Te VC (1998) Second cancers following in situ carcinoma of the breast. Int J Cancer 77: $392-395$ 
Fredriksson I, Liljegren G, Arnesson LG, Emdin SO, Palm-Sjovall M, Fornander T, Frisell J, Holmberg L (2001) Time trends in the results of breast conservation in 4694 women. Eur J Cancer 37: $1537-1544$

Fredriksson I, Liljegren G, Palm-Sjovall M, Arnesson LG, Emdin SO, Fornander T, Lindgren A, Nordgren H, Idvall I, Holmqvist M, Holmberg L, Frisell J (2003) Risk factors for local recurrence after breast-conserving surgery. Br J Surg 90: 1093-1102

Habel LA, Moe RE, Daling JR, Holte S, Rossing MA, Weiss NS (1997) Risk of contralateral breast cancer among women with carcinoma in situ of the breast. Ann Surg 225: 69-75

Harris J, Morrow M, Bonadonna G (1993) Cancer of the breast. In Cancer: Principal \& Practice of Oncology Vol. 4, Philadelphia: JB Lippcott

Hemminki K (2001) Genetic epidemiology - science and ethics on familial cancers. Acta Oncol 40: 439-444

Hemminki K, Granstrom C (2002) Morphological types of breast cancer in family members and multiple primary tumours: is morphology genetically determined? Breast Cancer Res 4: R7

Hemminki K, Li X, Plna K, Granstrom C, Vaittinen P (2001) The nationwide Swedish family-cancer database - updated structure and familial rates. Acta Oncol 40: $772-777$

Kerlikowske K, Molinaro A, Cha I, Ljung BM, Ernster VL, Stewart K, Chew K, Moore II DH, Waldman F (2003) Characteristics associated with recurrence among women with ductal carcinoma in situ treated by lumpectomy. J Natl Cancer Inst 95: 1692-1702

Kestin LL, Goldstein NS, Lacerna MD, Balasubramaniam M, Martinez AA Rebner M, Pettinga J, Frazier RC, Vicini FA (2000) Factors associated with local recurrence of mammographically detected ductal carcinoma in situ in patients given breast-conserving therapy. Cancer 88: 596-607

Khan A, Newman LA (2004) Diagnosis and management of ductal carcinoma in situ. Curr Treat Options Oncol 5: 131-144

Levi F, Te VC, Randimbison L, La Vecchia C (1997) Trends of in situ carcinoma of the breast in Vaud, Switzerland. Eur J Cancer 33: $903-906$

Li CI, Anderson BO, Daling JR, Moe RE (2003) Trends in incidence rates of invasive lobular and ductal breast carcinoma. JAMA 289: 1421-1424

Lindqvist R, Moller TR, Stenbeck M, Diderichsen F (2002) Do changes in surgical procedures for breast cancer have consequences for hospital mean length of stay? A study of women operated on for breast cancer in Sweden, 1980 - 1995. Int J Technol Assess Health Care 18: 566 - 575

Lishman SC, Lakhani SR (1999) Atypical lobular hyperplasia and lobular carcinoma in situ: surgical and molecular pathology. Histopathology 35: $195-200$

London SJ, Connolly JL, Schnitt SJ, Colditz GA (1992) A prospective study of benign breast disease and the risk of breast cancer. JAMA 267: $941-944$

Olsson S, Andersson I, Karlberg I, Bjurstam N, Frodis E, Hakansson S (2000) Implementation of service screening with mammography in
Sweden: from pilot study to nationwide programme. J Med Screen 7: $14-18$

Ottesen GL, Graversen HP, Blichert-Toft M, Christensen IJ, Andersen JA (2000) Carcinoma in situ of the female breast. 10 year follow-up results of a prospective nationwide study. Breast Cancer Res Treat 62: 197-210

Page DL (2004) Breast lesions, pathology and cancer risk. Breast J 10(Suppl 1): $\mathrm{S} 3-\mathrm{S} 4$

Page DL, Dupont WD (1990) Anatomic markers of human premalignancy and risk of breast cancer. Cancer 66: 1326-1335

Page DL, Dupont WD, Rogers LW, Rados MS (1985) Atypical hyperplastic lesions of the female breast. A long-term follow-up study. Cancer 55: $2698-2708$

Page DL, Jensen RA, Simpson JF, Dupont WD (2000) Historical and epidemiologic background of human premalignant breast disease. J Mammary Gland Biol Neoplasia 5: $341-349$

Pinder SE, Ellis IO (2003) The diagnosis and management of pre-invasive breast disease: ductal carcinoma in situ (DCIS) and atypical ductal hyperplasia $(\mathrm{ADH})$ - current definitions and classification. Breast Cancer Res 5: $254-257$

Plna K, Hemminki K (2001) Familial bladder cancer in the National Swedish Family Cancer Database. J Urol 166: 2129-2133

SAS/STAT ${ }^{\circledR}$ User's guide (1999). Cary, NC: SAS Inst. Inc.

Simon MS, Lemanne D, Schwartz AG, Martino S, Swanson GM (1993) Recent trends in the incidence of in situ and invasive breast cancer in the Detroit metropolitan area (1975-1988). Cancer 71: 769-774

The National Board of Health and Welfare Stockholm (2002) Cancer Incidence in Sweden, 2000. Stockholm: The National Board of Health and Welfare

Verkooijen HM, Fioretta G, Vlastos G, Morabia A, Schubert H, Sappino AP, Pelte MF, Schafer P, Kurtz J, Bouchardy C (2003) Important increase of invasive lobular breast cancer incidence in Geneva, Switzerland. Int $J$ Cancer 104: $778-781$

Warnberg F, Bergh J, Holmberg L (1999) Prognosis in women with a carcinoma in situ of the breast: a population-based study in Sweden. Cancer Epidemiol Biomarkers Prev 8: 769-774

Warnberg F, Bergh J, Zack M, Holmberg L (2001) Risk factors for subsequent invasive breast cancer and breast cancer death after ductal carcinoma in situ: a population-based case-control study in Sweden. Cancer Epidemiol Biomarkers Prev 10: 495-499

Warnberg F, Yuen J, Holmberg L (2000) Risk of subsequent invasive breast cancer after breast carcinoma in situ. Lancet 355: 724-725

Yau TK, Lau Y, Kong J, Yeung MW, Chan M, Sze WM, Cheung P, Lim BH, Lee A (2002) Breast conservation treatment in Hong Kong - early results of 203 patients: retrospective study. Hong Kong Med J 8: 322-328

Zahl PH, Strand BH, Maehlen J (2004) Incidence of breast cancer in Norway and Sweden during introduction of nationwide screening: prospective cohort study. BMJ 328: $921-924$ 